Faculty of Engineering

Faculty Publications

This is a post-print version of the following article:

A simple method for detection of low concentrations of fluoride in drinking water Vahid Moradia, Emmanuelle A. Caws, Peter M. Wilda, Heather L. Buckley 2019

The final publication is available at:

https://doi.org/10.1016/j.sna.2019.111684

Citation for this paper:

Moradia, V., Caws, E. A., Wilda, P. M., Buckley, H. L. (2019). A simple method for detection of low concentrations of fluoride in drinking water. Sensors and Actuators A: Physical, 303(1). https://doi.org/10.1016/j.sna.2019.111684 


\title{
A simple method for detection of low concentrations of fluoride in drinking water
}

\author{
Vahid Moradi ${ }^{a}$, Emmanuelle A. Caws ${ }^{b}$, Peter M. Wild ${ }^{a}$, Heather L. Buckley ${ }^{b, *, 1}$ \\ a Department of Mechanical Engineering, University of Victoria, 3800 Finnerty Rd, Victoria, BC, V8P 5C2, Canada \\ ${ }^{\mathrm{b}}$ Department of Civil Engineering, University of Victoria, 3800 Finnerty Rd, Victoria, BC, V8P 5C2, Canada
}

\section{A R T I C L E I N F O}

\section{Article history:}

Received 24 June 2019

Received in revised form

24 September 2019

Accepted 16 October 2019

Available online 21 October 2019

\section{Keywords:}

Fluoride

Drinking water

Optical fibre

Non-colourimetric detection

Trace element detection

Geogenic contamination

\begin{abstract}
A B S T R A C T
Naturally occurring elevated levels of fluoride in drinking water pose a health hazard throughout the developing world, with over 200 million people potentially impacted. In some cases, treatment methods or safer alternative sources are available, but robust, simple, affordable technologies for measuring fluoride in drinking water are absent. In this work, a simple method for fluoride detection is presented comprising a $35 \mathrm{~nm}$ aluminum coating on the distal tip of a length of single mode optical fiber. Broadband light is launched into the proximal end of the optical fiber and a portion of this light is reflected by the distal tip of the fiber, which is immersed in water containing an unknown concentration of dissolved fluoride. The intensity of the reflected light is detected by a photodiode connected to the proximal end of the fiber. The aluminum coating is removed from the distal tip by reaction with the dissolved fluoride at a rate that depends on the fluoride concentration and the intensity of the light reflected from the distal tip depends upon the thickness of this coating. Therefore, the rate at which the intensity of light detected by the photodiode decreases is correlated with the concentration of fluoride. The fabricated sensor measures fluoride concentration within the range of $0-5 \mathrm{mg} \mathrm{L}^{-1}$.
\end{abstract}

(c) 2019 Elsevier B.V. All rights reserved.

\section{Introduction}

Elevated fluoride concentrations in drinking water present significant risk to human health [1,2]. In regions where groundwater is the main source of drinking water, most notably in the East African Rift Valley and parts of India [3]. Sri Lanka and Northern China [4], over 200 million people consume water with naturallyoccurring fluoride levels that exceed the World Health Organization (WHO)-recommended limit of $1.5 \mathrm{mg} \mathrm{L}^{-1}[5,6]$. While optimal low concentrations (0.5-1 $\left.\mathrm{mg} \mathrm{L}^{-1}\right)$ prevent dental caries [7]. higher concentrations $\left(>1.5 \mathrm{mg} \mathrm{L}^{-1}\right)$ can lead to dental and skeletal fluorosis [8-14]. Managing the concentration of fluoride in drinking water supplies is crucial [15], and reliable, frequent measurement is essential to the effective provision of safe drinking water either by accessing alternative sources [16-20] or through affordable treatment [6,21-27].

Various methods are currently used to measure the concentration of fluoride in water [28] including ion-selective electrodes [29],

\footnotetext{
* Corresponding author.

E-mail address: hbuckley@uvic.ca (H.L. Buckley).

1 250-472-5879, https://oac.uvic.ca/greensafewater/, https://www.uvic.ca/ engineering/civil/people/home/hbuckley.php.
}

mass spectrometry [30], UV-visible spectroscopy [31], and fluorescence techniques [32]. However, these methods are not suitable for field use as they require careful preparation and analysis in a laboratory setting. For communities in low-resource contexts, there is a need for a robust device that can be used in the field, such as a handheld sensor [33].

The current industry standard for field measurement of fluoride is the SPADNS method, named after the chromophoric reagent 2(p-sulfophenylazo)-1,8-dihydroxy-3,6-napthalenedisulfonic acid) [34], developed by $\mathrm{HACH}$ and sold as a kit. This method measures the reaction of a red zirconium dye with fluoride in solution using a pocket colorimeter [35]. This method can measure fluoride in the range of $0.1-2 \mathrm{mg} \mathrm{L}^{-1}$ with high sensitivity [36], but its application is limited due to the requirement for manipulation of liquid reagents and possible contamination of glassware and equipment. Additionally, the SPADNS reagent for fluoride contains sodium arsenite, which is hazardous and proper disposal must follow strict protocols.

Alternative colorimetric fluoride detection methods have been developed that based on cell phone-compatible measurement kits, some of which are commercially available. In most of these methods, water is mixed with a liquid reagent in a sample chamber and characterized using the camera on a smart phone and custom software [37-39]. Using a variant of this approach, Vidan et al. react 
fluoride with the SPADNS reagent on filter paper rather than in solution, again using a cell phone camera and image processing software to quantify the analytes [40]. As with the HACH kit, all of these methods are limited by the requirement to manipulate and dispose of liquid reagents and by contamination between samples. Photographs of samples are also subject to variability in lighting and image quality.

Three studies describing fiber optic sensors for detection of fluoride in aqueous solutions have been identified in the literature; all are colorimetric in nature. Jadhav et al. measure fluoride concentration based on the interaction of the evanescent field of an in-fiber Bragg grating with a test solution to which an unspecified reagent is added. The Bragg wavelength, measured with an optical spectrum analyzer, shifts in response to changes in fluoride concentration [41]. Xiong et al. measure the concentration of fluoride using a photomultiplier tube positioned adjacent to an annular microfluidic channel, created by the space between concentric optical fiber and plastic tubing, containing the test solution mixed with a SPADNS reagent [42]. Pillai et al. measure attenuation of light transmitted through an optical fiber that is etched to enable optical interaction with the test solution to which a SPADNS reagent is added. Interrogation of this sensor is based on custom-built photo-electric circuit. All of these methods require availability of reagents or specialized optical equipment and are, therefore, not suitable for low cost field measurements.

Optical fiber sensors have been used for the detection of other chemistries, including $\mathrm{pH}$ monitoring [43-47], explosives detection $[48,49]$, methane $[50,51]$, and $\mathrm{CO}_{2}$ and supercritical $\mathrm{CO}_{2}$ measurement [52]. Recently, Prussian Blue has been deposited onto the tips of optical fibers and used for detection of peroxide in a fuel cell environment $[53,54]$.

In this work, we present a simple method to detect low concentrations of fluoride in drinking water. The tip of a single mode optical fiber is coated with aluminum using sputter deposition. Immersion of the coated fiber tip in a fluoride solution then leads to removal of the coating due to the reaction between fluoride and aluminum. Removal of the coating reduces the intensity of the light that reflects from the fiber tip, as illustrated in Fig. 1. The signal associated with this intensity change is shown to be proportional to the concentration of fluoride up to $5 \mathrm{ppm}$, allowing simple, reagent-free quantitation of fluoride concentration in water at relevant concentrations for drinking water characterization.

\section{Materials and methods}

\subsection{Chemicals}

Distilled water and sodium fluoride $(\mathrm{NaF}>0.99)$ (Sigma Aldrich) were used to prepare test solutions. $\mathrm{pH}$ was not explicitly controlled, but was consistently measured to be between $6.4 \pm 0.1$ for distilled water and $6.9 \pm 0.1$ for $80 \mathrm{mgL}^{-1}$ fluoride solution. To

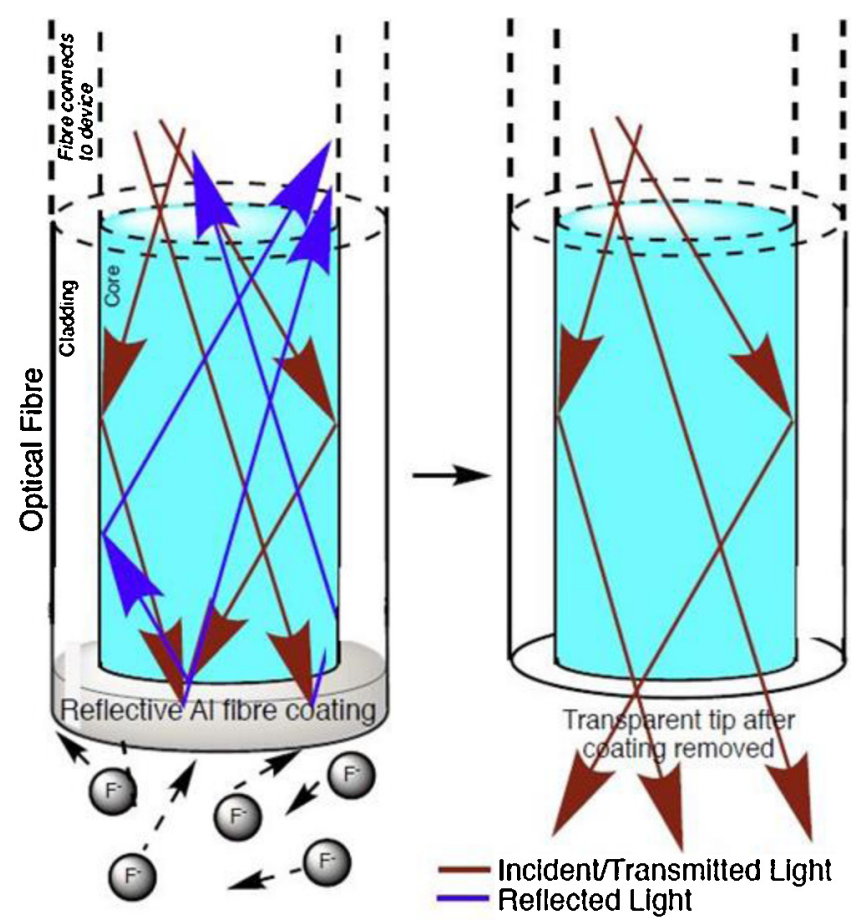

Fig. 1. The aluminum coated fiber tip. The fluoride ions remove the reflective aluminum layer from the fiber tip reducing the intensity of the reflected light.

prepare a $100 \mathrm{mgL}^{-1}$ fluoride stock solution, $0.105 \mathrm{~g}$ of NaF was dissolved in $500 \mathrm{~mL}$ of distilled water. The stock solution was then diluted to prepare solutions with concentrations of 1.0 (e.g. $0.1 \mathrm{~mL}$ stock solution and $9.9 \mathrm{~mL}$ of distilled water), 2.0, 3.5, 5.0, 10.0, 20.0, 40.0, and $80.0 \mathrm{mgL}^{-1} \mathrm{~F}$ - solution.

\subsection{Sensor fabrication}

The outer jacket and cladding were removed from $2 \mathrm{~cm}$ at the distal ends of 45 lengths of single mode optical fiber (Simplex 9/125, FS.COM-China). One tip of each of these fiber lengths was sputter coated with aluminum to a thickness of $35 \pm 0.5 \mathrm{~nm}$ (QUBE, Mantis Deposition-UK). This thickness was chosen because the sensor response time increases with coating thickness, but coatings of less than $35 \mathrm{~nm}$ break down easily when brought into contact with an aqueous solution.

\subsection{Instrumentation}

As shown in Fig. 2, the coated fiber tip is immersed in the test solution. $1550 \mathrm{~nm}$ light is transmitted from the broadband light source (BBS 1550, AFC Technologies), through the optical splitter

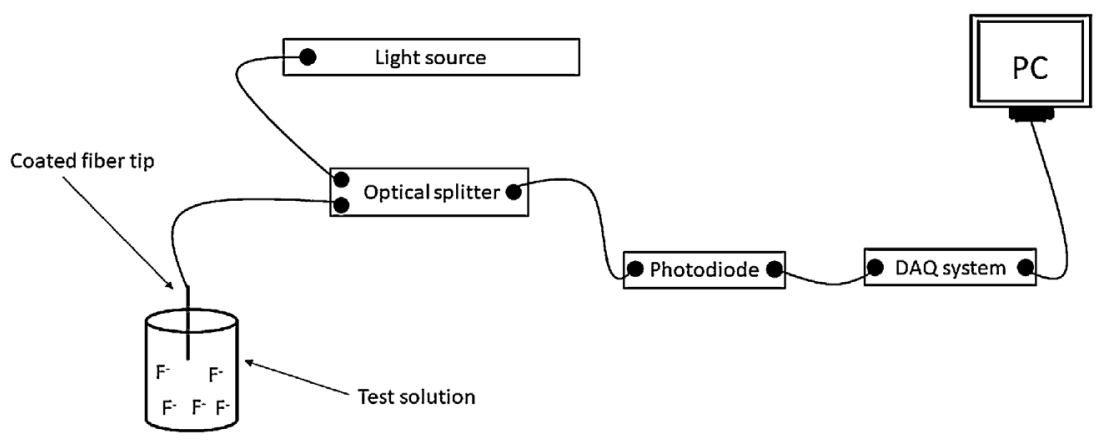

Fig. 2. Schematic drawing of the experimental set-up. 


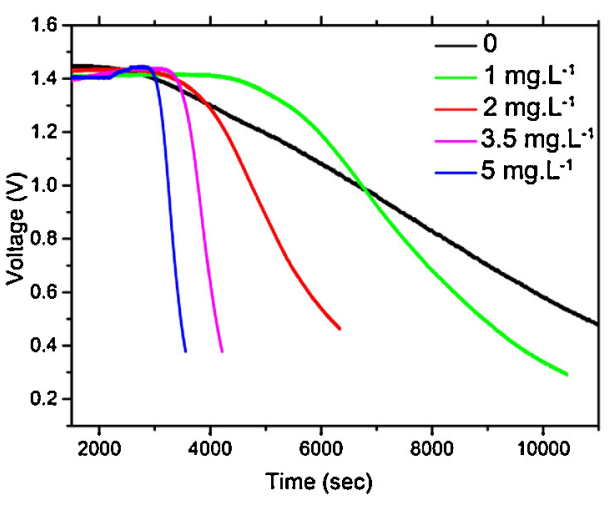

(a)

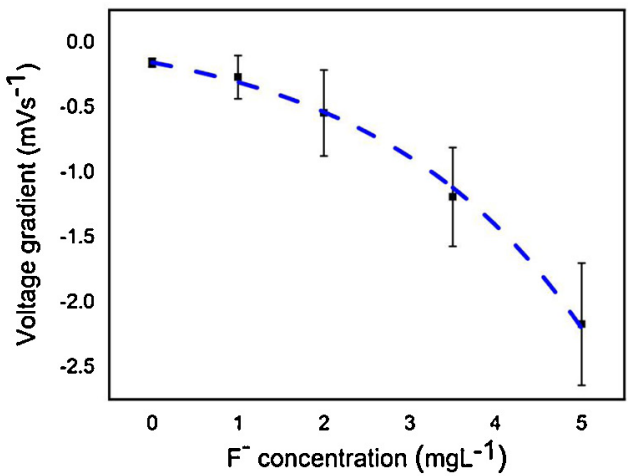

(b)

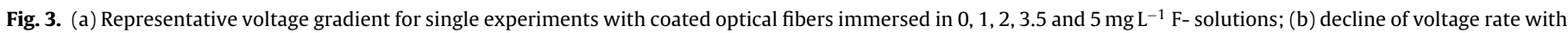
the increase in concentration of F- for $0,1,2,3.5$ and $5 \mathrm{mg} \mathrm{L}^{-1}$ of F- (mean values for five measurements, error bars correspond to standard deviations).

(BRR-35S, Blue Road Research Inc.) and to the coated fiber tip. Light reflected from the coated tip is transmitted back through the fiber, through the optical splitter to the photodiode (FDP 510, MenloSystems) that produces voltage proportional to the intensity of the reflected light. This signal is acquired by the data acquisition (DAQ) module (NI USB-6008, National Instruments) at a rate of $10 \mathrm{~Hz}$.

\subsection{Test procedures}

Each sensor tip was tested in a single solution sample. In total, 45 experiments were conducted using one sensor tip in each experiment. Five experiments were conducted at each of the following concentrations of $\mathrm{F}^{-}$: 0.0, 1.0, 2.0, 3.5, 5.0, 10.0, 20.0, 40.0 and $80.0 \mathrm{mgL}^{-1}$. In each experiment, the initial signal was approximately $1.4 \mathrm{~V}$ and this signal was recorded until it fell below approximately $0.4 \mathrm{~V}$.

\section{Results and discussion}

Fig. 3(a) depicts representative voltage versus time data for single experiments with coated optical fibers immersed in 0, 1.0, 2.0, 3.5 and $5.0 \mathrm{mgL}^{-1} \mathrm{~F}$ - solutions as shown in Table 1 . For each experiment, the voltage rate change, or gradient, with respect to time is calculated based on a linear fit of the data between $1.2 \mathrm{~V}$ and $0.6 \mathrm{~V}$. These gradient values are shown in Table S1 in the Supplementary information. Fig. 3(b) depicts average voltage gradient versus F- concentration for the sensor tips at each of the solution concentrations between 0 and $5 \mathrm{mg} \mathrm{L}^{-1}$. The gradient increases by two orders of magnitude, from $-1.6 \times 10^{-5} \mathrm{mVs}^{-1}$ to $-1.2 \times 10^{-3} \mathrm{mVs}^{-1}$, over this range.

An exponential curve was fit to the 25 voltage gradient values determined from the experiments in $0,1.0,2.0,3.5$ and $5.0 \mathrm{mgL}^{-1}$ F- solutions. The equation for this curve is:

$\Delta V / \Delta t=(-0.297) e^{-(0.413)[F-]}$

The regression coefficient for this fit is $R^{2}=0.993$. We do not postulate a specific mechanism of reaction of this complex heterogeneous system based on this fit, but rather note its empirical value for determination of the concentration of unknown samples within the $0-5 \mathrm{mg} \mathrm{L}^{-1} \mathrm{~F}$ - concentration range.

When an $\mathrm{Al}$ coated fiber tip is placed in contact with water, with no dissolved fluoride, amorphous oxide $\left(\mathrm{Al}_{2} \mathrm{O}_{3}\right)$ forms, dissolves in water, and then precipitates as aluminum hydroxide [55]. The rate of this reaction is significantly lower than reaction of Al with fluoride (as shown in Figs. 3a and 4a)

Fig. 4(a) depicts representative voltage versus time data for single experiments with coated optical fibers immersed in 10, 20, 40,

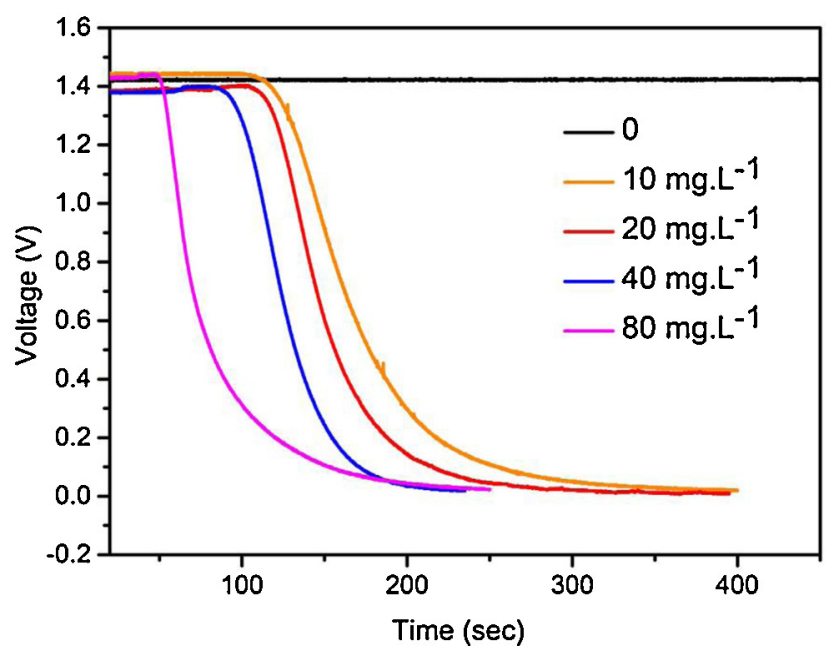

(a)

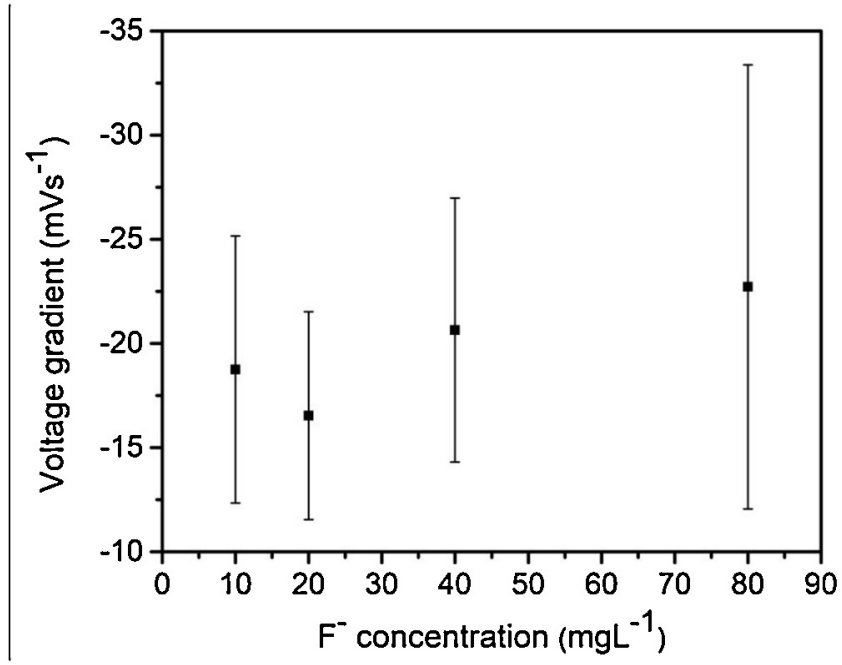

(b)

Fig. 4. (a) characterization of the sensor using solutions with $0,10,20,40$, and $80 \mathrm{mgL}^{-1}$ of F-; (b) decline of voltage change with the increase in concentration of $\mathrm{F}$ - for $10,20,40$, and $80 \mathrm{mgL}^{-1}$ of $\mathrm{F}$ - (mean values for five measurements, error bars correspond to standard deviations). 
Table 1

Mean and standard deviation of voltage gradient based on five tests at each $\mathrm{F}^{-}$concentration.

\begin{tabular}{|c|c|c|c|}
\hline $\mathrm{F}^{-}$concentration $\left(\mathrm{mgL}^{-1}\right)$ & Mean voltage gradient $(\Delta \mathrm{V} / \Delta \mathrm{t})$ & Standard deviation & Linear regression coefficient $\left(\mathrm{R}^{2}\right)$ \\
\hline 0 & $-1.6 \times 10^{-1} \mathrm{mVs}^{-1}$ & $\pm 3.3 \times 10^{-2}$ & 0.999 \\
\hline 1 & $-2.7 \times 10^{-1} \mathrm{mVs}^{-1}$ & $\pm 1.7 \times 10^{-1}$ & 0.997 \\
\hline 2 & $-5.4 \times 10^{-1} \mathrm{mVs}^{-1}$ & $\pm 3.3 \times 10^{-1}$ & 0.999 \\
\hline 3.5 & $-1.2 \mathrm{mVs}^{-1}$ & $\pm 3.8 \times 10^{-1}$ & 0.999 \\
\hline 5 & $-2.1 \mathrm{mVs}^{-1}$ & $\pm 4.3 \times 10^{-1}$ & 0.999 \\
\hline 10 & $-1.9 \times 10 \mathrm{mVs}^{-1}$ & \pm 6.4 & 0.999 \\
\hline 20 & $-1.6 \times 10 \mathrm{mVs}^{-1}$ & \pm 5.0 & 0.999 \\
\hline 40 & $-2.1 \times 10 \mathrm{mVs}^{-1}$ & \pm 6.3 & 0.999 \\
\hline 80 & $-2.3 \times 10 \mathrm{mVs}^{-1}$ & \pm 10.7 & 0.994 \\
\hline
\end{tabular}

and $80 \mathrm{mgL}^{-1} \mathrm{~F}$ - solutions as shown in Table 1. For each experiment, the voltage rate change, or gradient, with respect to time is calculated, as described earlier. These gradient values are shown in Table S1 in the Supplementary information. Fig. 4(b) depicts average voltage gradient versus F- concentration for the sensor tips at each of the solution concentrations between 10 and $80 \mathrm{mgL}^{-1}$.

From these figures, it is clear that there is no significant difference in the rate of aluminum removal from the sensor tips as a function of $\mathrm{F}^{-}$concentration in the $10-80 \mathrm{mgL}^{-1}$ range. At high $\mathrm{F}^{-}$ concentrations, the rates of reaction are too fast to resolve by this method. Depositing a thicker aluminum layer or a metal that reacts more slowly with fluoride could improve the sensitivity of this type of sensor at high fluoride concentrations. However, towards the goal of low-cost detection of fluoride in drinking water, resolution in the $0-5 \mathrm{ppm}$ concentration range, encompassing the $1.5 \mathrm{mg} \mathrm{L}^{-1}$ WHO recommended maximum fluoride concentration limit, is of greater practical utility.

\section{Conclusions}

In summary, we have fabricated fluoride sensors by depositing a $35 \mathrm{~nm}$ thick aluminum layer on the tip of a single mode optical fiber. Exposure to an aqueous fluoride solution removes the reflective aluminum layer from the sensor tip at a rate correlated to fluoride concentration and measured by voltage change at a photodiode. The single-use optical fiber tips are inexpensively fabricated, easily coupled to a simple photodiode, and are sensitive at fluoride concentrations ranging from 0 to $5 \mathrm{mg} \mathrm{L}^{-1}$ (encompassing the WHO maximum contaminant limit of $1.5 \mathrm{mg} \mathrm{L}^{-1}$ ), making them an important first step towards the development of low-cost, robust sensors for field detection of fluoride in drinking water.

\section{Declaration of Competing Interest}

The authors declare no conflicts of interest.

\section{Acknowledgements}

The authors would like to thank Jonathan Rudge of the Centre for Advanced Materials and Related Technology (CAMTEC) at the University of Victoria for his assistance with sputter-coating of the fiber tips. EAC acknowledges the NSERC USRA program and UN Association in Canada Green Spaces program for funding. HLB acknowledges CFI JELF and BCKDF for infrastructure support. PMW and HLB acknowledge the NSERC Discovery Grants program.

\section{Appendix A. Supplementary data}

Supplementary material related to this article can be found, in the online version, at doi:https://doi.org/10.1016/j.sna.2019. 111684.

\section{References}

[1] W.M. Edmunds, P.L. Smedley, in: O. Selinus (Ed.), Fluoride in Natural Waters, in Essentials of Medical Geology: Revised Edition, Springer, Netherlands: Dordrecht, 2013, pp. 311-336.

[2] E. Bazrafshan, K.A. Ownagh, A.H. Mahvi, Application of electrocoagulation process using Iron and aluminum electrodes for fluoride removal from aqueous environment, E-J. Chem. 9 (4) (2012).

[3] UNICEF, State of Art Report on Extent of Fluoride in Drinking Water and the Resulting Endemicty in India, 1999, New Dehli.

[4] R. Wu, et al., Modeling contaminant concentration distributions in China's centralized source waters, Environ. Sci. Technol. 45 (14) (2011) 6041-6048.

[5] M. Amini, et al., Statistical modeling of global geogenic fluoride contamination in groundwaters, Environ. Sci. Technol. 42 (10) (2008) 3662-3668.

[6] S. Jagtap, et al., Fluoride in drinking water and defluoridation of water, Chem. Rev. 112 (4) (2012) 2454-2466.

[7] M. Fu, et al., Natrium fluoride influences methylation modifications and induces apoptosis in mouse early embryos, Environ. Sci. Technol. 48 (17) (2014) 10398-10405.

[8] A. Balan Pillai, B. Varghese, K.N. Madhusoodanan, Design and development of novel sensors for the determination of fluoride in water, Environ. Sci. Technol. 46 (1) (2012) 404-409.

[9] WHO, Guidelines for Drinking-Water Quality, Vol. 1, 2nd ed, 1993, pp. 2011, Geneva.

[10] B.D. Turner, P. Binning, S.L.S. Stipp, Fluoride removal by calcite: evidence for fluorite precipitation and surface adsorption, Environ. Sci. Technol. 39 (24) (2005) 9561-9568

[11] T. Jayarathne, et al., Emissions of fine particle fluoride from biomass burning, Environ. Sci. Technol. 48 (21) (2014) 12636-12644.

[12] K. Brindha, et al., Fluoride contamination in groundwater in parts of Nalgonda District, Andhra Pradesh, India, Environ. Monit. Assess. 172 (1) (2011) 481-492.

[13] A.A. Mohammadi, et al., Skeletal fluorosis in relation to drinking water in rura areas of West Azerbaijan, Iran, Sci. Rep. 7 (1) (2017) 17300.

[14] H. Biglari, et al., Geochemical study of groundwater conditions with special emphasis on fluoride concentration, Iran, Desalin. Water Treat. 57 (47) (2016) 22392-22399.

[15] K. Jha, et al., Hirudotherapy in medicine and dentistry, J. Clin. Diagn. Res.: JCDR 9 (12) (2015), p. ZE05-ZE7.

[16] N. Subba Rao, Groundwater quality: focus on fluoride concentration in rural parts of Guntur district, Andhra Pradesh, India, Hydrol. Sci. J. 48 (5) (2003) $835-847$.

[17] J.J. Carrillo-Rivera, A. Cardona, W.M. Edmunds, Use of abstraction regime and knowledge of hydrogeological conditions to control high-fluoride concentration in abstracted groundwater: san Luis Potosí basin, Mexico, J. Hydrol. 261 (1) (2002) 24-47.

[18] J.E. Podgorski, et al., Prediction modeling and mapping of groundwater fluoride contamination throughout India, Environ. Sci. Technol. 52 (17) (2018) 9889-9898

[19] L. Craig, et al., Recommendations for fluoride limits in drinking water based on estimated daily fluoride intake in the Upper East Region, Ghana, Sci. Total Environ. 532 (2015) 127-137.

[20] J.-m. Mwenge Kahinda, A.E. Taigbenu, J.R. Boroto, Domestic rainwater harvesting to improve water supply in rural South Africa, Phys. Chem. Earth Parts A/B/C 32 (15) (2007) 1050-1057.

[21] M. Habuda-Stanić, M.E. Ravančić, A. Flanagan, A review on adsorption of fluoride from aqueous solution, Materials (Basel, Switzerland) 7 (9) (2014) 6317-6366.

[22] N. Das, P. Pattanaik, R. Das, Defluoridation of drinking water using activated titanium rich bauxite, J. Colloid Interface Sci. 292 (1) (2005) 1-10.

[23] A.Z. Haddad, et al., On the conversion of bauxite ores to highly activated alumina media for water remediation, Adv. Sustain. Syst. (2019) 1900005 , $\mathrm{O}(0)$.

[24] W.-W. Choi, K.Y. Chen, The removal of fluoride from waters by adsorption, J. Am. Water Works Assoc. 71 (10) (1979) 562-570.

[25] H.L. Buckley, et al., Addressing technical barriers for reliable, safe removal of fluoride from drinking water using minimally processed bauxite ores, Dev. Eng. 3 (2018) 175-187. 
[26] M. Mohapatra, et al., Review of fluoride removal from drinking water, J. Environ. Manage. 91 (1) (2009) 67-77.

[27] L. Osterwalder, et al., Multi-criteria assessment of community-based fluoride-removal technologies for rural Ethiopia, Sci. Total Environ. 488-489 (2014) 532-538

[28] A. Dhillon, M. Nair, D. Kumar, Analytical methods for determination and sensing of fluoride in biotic and abiotic sources: a review, Anal. Methods 8 (27) (2016) 5338-5352.

[29] P. Anzenbacher, et al., Simple electrooptical sensors for inorganic anions, Org. Lett. 7 (22) (2005) 5027-5030

[30] S. Kage, et al., Determination of fluoride in human whole blood and urine by gas chromatography-mass spectrometry, Forensic Toxicol. 26 (1) (2008) 23.

[31] Y. Li, et al., Self-assembly of graphene oxide with a silyl-appended spiropyran dye for rapid and sensitive colorimetric detection of fluoride ions, Anal. Chem. 85 (23) (2013) 11456-11463.

[32] Y. Bao, et al., A n̈aked eyeänd ratiometric fluorescent chemosensor for rapid detection of $\mathrm{F}^{-}$based on combination of desilylation reaction and excited-state proton transfer, Chem. Commun. 47 (13) (2011) 3957-3959.

[33] Hans-Peter Bader, M.B. Anja Bretzler, Geogenic Contamination Handbook Geogenic Contamination Handbook, Eawag: Swiss Federal Institute of Aquatic Science and Technology, Seitzerland, 2017.

[34] SPADNS, ACS Reagent Chemicals, American Chemical Society, 2017.

[35] G. Brambilla, V. Finazzi, D.J. Richardson, Ultra-low-loss optical fiber nanotapers, Opt. Express 12 (10) (2004) 2258-2263.

[36] Fluoride, SPADNS Method (0.1 to $2.0 \mathrm{mg} / \mathrm{L}), \mathrm{HACH}$ COMPANY, AccuVac ${ }^{\circledR}$ Ampuls, USA, 2017

[37] I. Hussain, K.U. Ahamad, P. Nath, Low-cost, robust, and field portable smartphone platform photometric sensor for fluoride level detection in drinking water, Anal. Chem. 89 (1) (2017) 767-775.

[38] S. Levin, et al., Monitoring of fluoride in water samples using a smartphone, Sci. Total Environ. 551-552 (2016) 101-107.

[39] Y. Wen, et al., Microaxicave colour analysis system for fluoride concentration using a smartphone, RSC Adv. 7 (67) (2017) 42339-42344.

[40] E. Vidal, et al., Micropaper-based analytical device ( $\mu$ PAD) for the simultaneous determination of nitrite and fluoride using a smartphone, Microchem. J. 143 (2018) 467-473.

[41] M.S. Jadhav, et al., Fluoride contamination sensor based on optical fiber grating technology, Opt. Fiber Technol. 38 (2017) 136-141.

[42] Y. Xiong, et al., Optical sensor for fluoride determination in tea sample based on evanescent-wave interaction and fiber-optic integration, Talanta 174 (2017) 372-379.

[43] A.K. Pathak, D.K. Chaudhary, V.K. Singh, Broad range and highly sensitive optical pH sensor based on Hierarchical $\mathrm{ZnO}$ microflowers over tapered silica fiber, Sens. Actuators A Phys. 280 (2018) 399-405.

[44] W. Li, et al., An experimental study of $\mathrm{pH}$ optical sensor using a section of no-core fiber, Sens. Actuators A Phys. 199 (2013) 260-264.

[45] S.H. Alabbas, et al., Factors affectig the response time of an optical-fibre reflectance pH sensor, Sens. Actuators A Phys. 51 (2) (1995) 129-134.

[46] S. Islam, et al., Sol-gel based fiber optic pH nanosensor: structural and sensing properties, Sens. Actuators A Phys. 238 (2016) 8-18.

[47] S. Islam, et al., Surface functionality and optical properties impact of phenol red dye on mesoporous silica matrix for fiber optic $\mathrm{pH}$ sensing, Sens. Actuators A Phys. 276 (2018) 267-277.

[48] R. Orghici, et al., A microring resonator sensor for sensitive detection of 1,3,5-Trinitrotoluene (TNT), Sensors 10 (7) (2010) 6788-6795.
[49] F. Chu, J. Yang, Coil-shaped plastic optical fiber sensor heads for fluorescence quenching based TNT sensing, Sens. Actuators A Phys. 175 (2012) 43-46.

[50] M. Benounis, et al., NIR and optical fiber sensor for gases detection produced by transformation oil degradation, Sens. Actuators A Phys. 141 (1) (2008) $76-83$.

[51] C. Ronot, et al., Optimization and performance of a specifically coated intrinsic optical-fibre sensor for the detection of alkane compounds, Sens. Actuators A Phys. 42 (1) (1994) 529-534

[52] G. Burton, et al., Fiber refractometer to detect and distinguish carbon dioxide and methane leakage in the deep ocean, Int. J. Greenh. Gas Control. 31 (2014) 41-47.

[53] H.A. Khorami, et al., Spectroscopic detection of Hydrogen peroxide with an optical fiber probe using chemically deposited Prussian blue, Electrochim. Acta 115 (2014) 416-424.

[54] J.F. Botero-Cadavid, et al., Detection of hydrogen peroxide using an optical fiber-based sensing probe, Sens. Actuators B Chem. 185 (2013) 166-173.

[55] W. Vedder, D.A. Vermilyea, Aluminum + water reaction, Trans. Faraday Soc. 65 (1969) 561-584, http://dx.doi.org/10.1039/TF9696500561.

\section{Biographies}

Dr. Vahid Moradi received his B.S (2008) and M.S (2010) in Applied Chemistry. During his M.S, he worked on the design and optimization of reactors including a reactor for liquid-liquid extraction, and a UV-assisted reactor for wastewater treatment. He received his Ph.D in Mechanical Engineering at University of Victoria (2017). His focus was conducting research on synthesis of photocatalyst materials, photocatalytic reactions and band-gap engineering of materials, which were used as self-cleaning surfaces and water disinfection. He joined Institute for Integrated Energy Systems (IESVic) in 2017 as research associate and worked on fabrication of chemical sensors using optical fibers.

Emmanuelle Caws is a Research Assistant in the Department of Civil Engineering at University of Victoria. She has a Bachelor of Engineering in Environmental Engineering from the University of Guelph in 2019. Her research interests focus on clean drinking water solutions, especially for detection and removal of trace contaminants in water.

Peter M. Wild, PhD is a Professor in the Department of Mechanical Engineering at the University of Victoria. He holds the Natural Sciences and Engineering Research Council (NSERC) Chair in Sustainable Energy Systems Design and is the Director of the Institute for Integrated Energy Systems at UVic (IESVic). Dr. Wild's research interests include: optical sensors for industrial, environmental and biomedical applications impacts of integration of renewable energy generation into existing grids; and renewable energy generation technologies.

Dr. Heather Buckley is an Assistant Professor of Civil Engineering, an Adjunct Professor of Chemistry at the University of Victoria and a member of IESVic and CAMTEC UVic's Centre for Advanced Materials and Related Technologies. She holds a PhD in Chemistry from the University of California Berkeley and is a German BMBF Green Talents and US Department of State International Fulbright S\&T Alumna. Her interdisciplinary research group tackles green chemistry and engineering problems to improve human and environmental health, with a focus on drinking water. Her interests are in designing tools for better environmental monitoring and strategies for the proactive use of safer alternatives. This empowers communities and industrial partners towards environmental stewardship and better public health outcomes. 